\title{
Contribuições teóricas e reflexões sobre a abordagem entrepreneuring para 0 empreendedorismo
}

Luccas Santin Padilha ${ }^{1}$ Dulcimar José Julkovski ${ }^{1}$ Hilka Machado ${ }^{1}$ Juliano Danilo Spuldaro ${ }^{1}$

${ }^{1}$ Universidade do Oeste de Santa Catarina (UNOESC) 


\title{
CONTRIBUIÇÕES TEÓRICAS E REFLEXÕES SOBRE A ABORDAGEM ENTREPRENEURING PARA O EMPREENDEDORISMO
}

\begin{abstract}
Resumo
A abordagem entrepreneuring mostra-se em crescimento nos estudos em empreendedorismo. Este trabalho buscou compreender a evolução das discussões sobre a abordagem entrepreneuring no campo de estudo do empreendedorismo, retratando as subcategorias com as constituições. Com isso, o estudo pretendeu evidenciar por meio de uma revisão da literatura a evolução das percepções e seus reflexos no campo de estudo. A metodologia utilizada foi revisão de literatura. Este trabalho procura contribuir para a reflexão sobre a abordagem entrepreneuring e suas contribuições para o campo de estudo do empreendedorismo. $\mathrm{O}$ entrepreneuring, assim, se apresenta como um fenômeno complexo, não-linear e com aspectos econômicos, sociais, institucionais e culturais por meio das ações de um indivíduo ou grupo de indivíduos.
\end{abstract}

Palavras-chave: Entrepreneuring. Contribuições teóricas. Empreendedorismo. Practice turn.

\section{Introdução}

Mesmo que para muitos o campo de pesquisa em empreendedorismo seja relativamente novo, os pensamentos pioneiros sobre o termo não são (York \& Venkataraman, 2010). Para Shane e Venkataraman (2000), é quase impossível o entendimento do assunto apenas por características pessoais, além de ser importante uma contextualização na influência de diversas situações e do próprio ambiente onde este fenômeno é desenvolvido. Shane (2003) enfatiza o estudo do empreendedorismo com uma abordagem interdisciplinar para a elaboração de um esquema conceitual que possa melhor compreender o assunto. Entretanto, existem diversas tentativas tradicionais de teorizar processos empreendedores e a abordagem entrepreneuring está no processo empreendedor, sendo aquele que envolve novas criações de risco e que foram intencionalmente planejadas, ou seja, uma trajetória linear (Steyaert, 2007). É nessa perspectiva que se busca compreender o entrepreneuring como um fenômeno complexo, não-linear e inerentemente aberto (Johannisson, 2011; Sorenson, 2006; Steyaert, 2007; Wright \& Marlow, 2011).

Em pesquisas empíricas com empreendedores (bem-sucedidos) três pontos principais são citados, o primeiro, os empreendedores bem-sucedidos gastam mais tempo em ação e visão concreta do que em planejamento (Jones \& Li, 2017). Em segundo lugar, ao longo dos anos (1976-2009) a pesquisa empírica repetida, que cada vez mais, maior parte do orçamento de tempo é gasto em ação concreta, presumivelmente também relacionamento, do que planejamento e visão. As duas primeiras podem ser explicadas, devido a um ambiente cada vez mais turbulento e mundo complexo. Em terceiro lugar, proprietários-gerentes são capazes de manter sua preocupação com a visão mais voltada ao negócio, ou mais viável do que líderes profissionais. Estes resultados empíricos estão claramente em contraste com a imagem do empreendedorismo como uma atividade planejada e que caracteriza abordagens racionalistas ao empreendedorismo (Pinchot, 1985; Schatzki, 2001; Johannisson, 2009; Jones \& Li, 2017).

Assim, este trabalho tem como objetivo compreender a evolução das discussões sobre a abordagem entrepreneuring no campo de estudo do empreendedorismo. Quanto à fonte de dados, foi realizada uma revisão da literatura em duas bases de dados, sendo elas, Scopus e Web of Science, com as palavras-chave, entrepreneuring inseridas na busca de abstract, title $e$ keywords. A partir de uma amostra de 182 artigos coletados nas bases de dados citadas, foi incluído o critério de seleção por área do conhecimento bussiness and administration, e por tipo 
removido 28 duplicados e restaram 32 artigos que possuiam relação direta com o tema, os quais foram analisados, com foco na revisão da literatura, análise e resultados.

Esse estudo contribui para a compreensão das discussões referentes a entrepreneuring para o campo de estudo do empreendedorismo, e como está estabelecido na literatura os estudos sobre o tema, não somente com o viés teórico, mas também com perspectivas de suprir o campo empírico. A primeira parte do trabalho apresenta uma revisão da literatura trazendo uma introdução a abordagem do entrepreneuring. Após essa discussão, são apresentadas as perspectivas metodológicas. Na sequência é apresentado a análise e discussão dos resultados e por fim, apresenta-se as considerações finais.

\section{Referencial Teórico}

\subsection{Entrepreneuring}

O empreendedorismo costuma ser definido como o processo pelo qual as pessoas iniciam e desenvolvem seus negócios. É um fenômeno complexo, que envolve o empreendedor, a empresa e o cliente, que fazem parte deste processo. $\mathrm{O}$ empreendedorismo se torna fator primordial, fazendo com que os negócios sobrevivam e prosperem num ambiente econômico e de mudanças sejam elas culturais, sociais ou geográficas (Davidssson, 2004).

Drucker (1985) afirma que o empreendedorismo "não é nem arte nem ciência, mas prática." Entretanto, em oposição a essa visão, propõem-se que o empreendedorismo pode ser tanto arte quanto ciência (Hjorth et al. 2003). A volatilidade do mundo, bem como suas diferentes formas de relações associadas a imaginação, pode ser usada para criar um empreendimento concreto. O estudo empreendedorismo é emergente e aspira a suas teorias próprias. A literatura científica também possui inúmeros modelos que, segundo seus autores, fornece a imagem final do fenômeno do empreendedorismo e com diferentes perspectivas, o que torna o estudo ainda mais complexo (Farah, Cavalcanti, \& Marcondes, 2008).

Um pouco pode ser explicado pela teoria econômica, sendo que, o termo entrepreneur não tem uma definição, mas Schumpeter (1982) associa o termo à inovação para explicar o desenvolvimento econômico. Na perspectiva comportamentalista, é nas características do entrepreneurs, ou seja, de um tipo de comportamento que se identifica quem é o entrepreneur. Aqui o termo não é traduzido por empresário, mas por empreendedor e este é entendido mais por seus atributos psicológicos e menos por sua ação econômica. Esta, na verdade, seria consequência dos primeiros (Schumpeter, 1982). Os termos, empreendedor e empreender, inicialmente, tomados da linguagem cotidiana, ganharam caráter de conceito acadêmico e posteriormente foram popularizados levando consigo conotações econômicas e/ou comportamentais advindas do mundo acadêmico. Comumente, entende-se por empreendimento alguma realização ou feito não necessariamente econômico. Mas em geral, carrega conotação econômica, se referindo a alguma atividade remunerada, não necessariamente empresarial (Davidsson, 2004).

O empreendedorismo como um conjunto de estratégias para criação e obtenção de valor, crescimento ou sobrevivência das empresas depende do conhecimento experimental e, portanto, epistemológico ou baseado nas habilidades, tornando-se cada vez mais instrumentais para corrigir as ineficiências ou fornecer novas soluções, bens e serviços (Shane, 2000). Com a especialização do conhecimento, a descoberta de oportunidades comerciais e a atividade empreendedora se intensificam, e Hisrich, Peters e Shepherd (2009) destacam que neste mesmo período, o termo era utilizado para se referir às ocupações específicas, porém, a continuidade da evolução foi se ampliando e a figura do indivíduo empreendedor tornou-se mais relevante que sua ocupação. 
Nesse sentido, é importante citar que estas abordagens possibilitam a compreensão de que o fenômeno do empreendedorismo é complexo demais para ser analisado apenas de um ponto de vista (Baron \& Shane, 2007). Isso sinaliza a necessidade de um quadro que reconheça o empreendedorismo como uma prática (diária), incluindo rotinas, bem como improvisação, a fim de lidar com coincidência (Steyaert \& Katz, 2004). Empreendedorismo como um processo de iniciativa de implementar novos negócios ou mudanças envolvendo inovações e riscos, leva em conta o conhecimento tácito e relacionamento pessoal que parecem permanecer relevantes, também nos tempos digitais atuais, quando o conhecimento codificado e parcerias formais dominam o discurso público sobre como criar um desenvolvimento sustentável em empresas e sociedades (Steyaert \& Katz, 2004).

A abordagem proposta para o empreendedorismo, o entrepreneuring, como refletido nas práticas cotidianas, enquadrada por uma ontologia de tornar-se, apoiada por phronesis (Sabedoria Prática) como uma virtude intelectual e realizado por meio de uma metodologia enativa (interação dinâmica entre um organismo atuante e seu ambiente que combina suas ações com as exigências de determinada situação) traz importantes mensagens para a comunidade de pesquisa (Pinchot, 1985; Schatzki, 2001; Johannisson, 2009; Jones \& Li, 2017). Desmitifica as realizações heroicas, e promove o empreender associando-o com a vida cotidiana, não apenas para restabelecer como uma atividade humana fundamental, central no homem, mas na busca contínua de identidade e significado da vida (Johannisson, 2009; Jones \& Li, 2017).

A crítica da abordagem entrepreneuring está no processo empreendedor predominantemente, sendo aquele que envolve novas criações (Steyaert, 2007). É nessa perspectiva que se busca compreender o entrepreneuring como um fenômeno complexo, nãolinear e inerentemente aberto (Sorenson, 2006; Steyaert, 2007; Johannisson, 2011; Wright \& Marlow, 2011). O entrepreneuring está alinhado a perspectiva de um conglomerado de práticas transindividuais (Johannisson, 2011), propondo do tempo e espaço como modo de exploração. Levando em consideração todos os atos e eventos, também aqueles que parecem muito relativos (Engstrom, 2012; Steyaert, 2004) para a maioria das análises. Pode-se conceituar entrepreneuring como a inter-relação de vários ritmos, imerso em mundo detalhado, intrincado e dinâmico, em vez de como um ponto estático (Verduyn, 2015). Ou como esforços para criar novos ambientes econômicos, sociais, institucionais e culturais por meio das ações de um indivíduo ou grupo de indivíduos. Assim, vemos o entrepreneuring como um processo emancipatório com amplo potencial de mudança com perspectiva prática (Rindova, Barry \& Ketchen, 2009).

As concepções processuais e organizacionais desse processo emancipatório, apresentam como característica fundamental, articulações entre um conjunto de questões que apontam para a consideração do empreendedorismo enquanto um processo pré-organizacional focado em oportunidades. Esses posicionamentos se afastam de visões que enfatizam a importância exclusiva do papel desempenhado por indivíduos empreendedores e dos resultados econômicos isolados de suas atuações e intervenções, contribuindo de forma importante para a geração de novas evidências sobre o fenômeno (Rindova, Barry \& Ketchen, 2009; Shane, 2012; Davidsson, 2015). A prática no empreendedorismo, emerge por meio de inter-relações entre o contexto de tempo e de espaço sendo um conjunto de atividades de intenções, motivações, e ações para executar atividades. Essas iniciativas, que visam apreender a prática, devem integrar as ações individuais com as atividades organizacionais de modo a possibilitar avanços de desempenho (Whittington, 2006). 


\section{Procedimentos Metodológicos}

Esta pesquisa apresenta uma revisão da literatura sobre entrepreneuring, buscando evidenciar as relações entrepreneuring existentes na literatura, promovendo reflexões da abordagem para o estudo do empreendedorismo. O trabalho é concentrado em artigos publicados em periódicos internacionais de língua inglesa e francesa, selecionados na base de dados Scopus e Web of Science, o critério referente ao intervalo de tempo foi aberto, levando em consideração que busca-se a totalidade das bases então selecionadas. As revisões são particularmente úteis para integrar as informações de um conjunto de estudos realizados separadamente sobre determinada situação ou fenômeno, que pode apresentar resultados conflitantes e/ou coincidentes, bem como identificar temas que necessitam de evidência, auxiliando na orientação para investigações futuras (Akobeng, 2005).

Desta forma, criou-se o fluxo de trabalho em sete passos (Figura 1). Inicia-se com a elaboração da questão da pesquisa como passo inicial. No passo 2, elabora-se as strings utilizadas na busca nas bases de dados. Procedendo a busca, no passo 3 evidencia-se os resultados dessa busca e passa-se para o passo 4, sendo selecionados 34 artigos que abordam entrepreneuring nas palavras-chave, resumo e título, destes foram analisados em sua totalidade. Realizado o passo 4, efetivamos o passo 5 foram analisados os artigos com a análise das informações abordadas pelos autores, no passo 6 passamos a analisar os resultados e a escrever as discussões, e por fim, no passo 7 apresenta-se as contribuições da pesquisa e as conclusões, bem como limitações e pesquisas futuras. Para desenvolver a classificação dos artigos utilizouse o software State of the Artthrough Systematic Review (StArt).

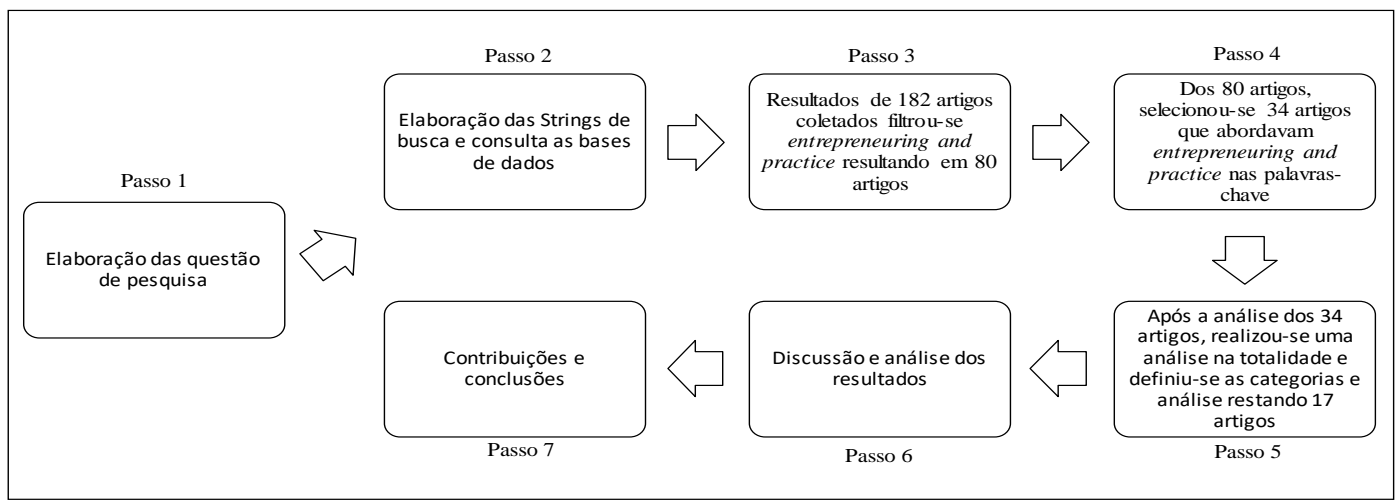

Figura 1: Fluxo de trabalho da pesquisa

Sobre os procedimentos, para a análise dos dados utilizou-se análise de conteúdo (Bardin, 2011), que possibilitou elencar algumas categorias a posteriori da leitura e análise dos artigos selecionados, desta forma com maior aprofundamento, destaca-se as categorias definidas para esse estudo como: (1) Entrepreneuring e seus desdobramentos (aborda trajetória do conceito, Practice Turn e apresenta construção da teoria) e esta, são divididos em seis subcategorias sendo elas: Promovem uma discussão sobre empreendedorismo com a perspectiva prática, Improvisação e Bricolagem, Compreensão do contexto por empreendedores, Redes de empreendedorismo, Empreendedorismo de gênero e Legitimação de risco.

\section{Análise e Discussão dos Resultados}

Diversos campos de estudo e mesmo diversos conceitos (Reed, 2006; Raelin, 2009; Born, 2010; Reid, 2011; Brown, 2012; Stockhammer, 2012; Lodhia \& Jacobs 2013;

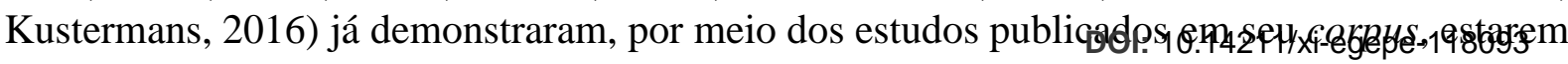


alguns autores argumentam - cada um sobre seu campo ou objeto - que a virada não está completa (Maciel \& Mussi, 2013) outros buscam evidenciar que ela é necessária, promissora ou já ocorreu (Reed, 2006; Brown, 2012; Stockhammer, 2012 Lodhia \& Jacobs 2013, Kustermans, 2016). Além destes, há ainda aqueles que advogam que o campo ainda resiste a olhar o fenômeno com o olhar da prática (Raelin, 2009; Reid, 2011). Há por fim, quem diga que o fenômeno extrapolou a amplitude de uma prática e que, portanto, para compreende-lo é preciso um olhar mais amplo ainda (Born, 2010; Felix \& Oliveira, 2019).

O empreendedorismo, assim como a estratégia empresarial, por exemplo - para reorientar o debate para dentro dos estudos organizacionais - discute de modo consistente este olhar a partir do entendimento que proceder a virada da prática consiste em perceber sistematicamente a localização do social na substância das próprias práticas (Maciel \& Mussi, 2013). Isto é possível a partir de um quadro analítico amplo, que considere campos de organizações, comunidades de praticantes e a observação da prática em si e análise de modo comparativo (Whittington, 2011). Um último elemento essencial deste esforço de compreensão da realidade está ligado a compreender a agência dos indivíduos, especialmente no que tange à importância do caráter de fluxo contínuo de suas ações. Sob a égide da virada da prática e levando esta propriedade em consideração, alguns campos passaram a adotar a terminologia que no português equivale ao gerúndio com "ndo" ("ing" no inglês) ao final do termo que dá nome ao fenômeno para representar um campo ou conceito onde a virada está sendo ou foi processada, a exemplo de, na estratégia ter sido amplamente adotado o termo "strategizing" (Jarzabkowski, Balogun, \& Seidl, 2007). Dessa forma, o termo entrepreneuring representa que o campo do empreendedorismo avalia em que medida a virada da prática está consolidada em seu bojo e até que ponto o olhar que ela preconiza pode ser importante para a compreensão do fenômeno em questão, algo para o que a discussão e análise estruturadas aqui visa contribuir.

\subsection{Entrepreneuring e seus desdobramentos}

O empreendedorismo como prática ou entrepreneuring, estes alicerçados no conceito de "practice turn", a discussão do conceito mostra-se incipiente e contemporânea nas ciências sociais. A teoria chama a atenção no cenário contemporâneo como um meio válido para entender como as pessoas fazem as coisas em um nível individual, um nível coletivo e as ações que navegam entre os dois níveis. A "prática" é um tipo de desempenho humano rotinizado que consiste em vários elementos interconectados entre si (Whittington, 2006).

A prática possui algumas vertentes como, a teoria da prática social estuda a relação entre os indivíduos e seu ambiente. Enquanto as abordagens de práticas tradicionais focalizam os hábitos e o conhecimento tácito dos atores para entender a repetição nas estruturas de campo e na estruturação de campo dos atores (Giddens 1982; Bourdieu, 2010), pesquisas sociais mais recentes focam em como os atores realizam tarefas em cenários complexos (Orr, 1996). Em sua iteração contemporânea na pesquisa em organização, o instinto de prática estuda a inter-relação entre organizações, as práticas atuais de organização e os praticantes que as encenam (Whittington, 2006).

Em essência, a existência de uma prática depende necessariamente da existência e da interconectividade específica dos elementos que não podem ser reduzidos a elementos isolados. Da mesma forma, uma prática representa um padrão que pode ser preenchido por uma multiplicidade de ações únicas e muitas vezes únicas (re) produzindo a prática. Ou seja, o único praticante individual, age então como o "portador" de uma prática e, de fato, de muitas práticas diferentes que não precisam ser coordenadas umas com as outras (Whittington, 2006; Ross, 2019).

No empreendedorismo como prática, um praticante de empreendedorismo carrega 
e desejar, por e sobre empreendedorismo. Essas atividades de pensamento convencional, saber e desejar são elementos e qualidades necessárias de práticas empreendedoras nas quais o empreendedor único participa, e não necessariamente possua qualidades de empreendedor (Yearworth, Ormerod, \& White, 2019).

Desta forma, as práticas de empreendedorismo são formas rotineiras em que os profissionais de empreendedorismo movem corpos, manipulam objetos, tratam assuntos, descrevem coisas e compreendem o mundo. Schatzki (2001) resume esses elementos no termo abrangente de "campo de práticas", compreendendo conhecimento, significado, atividade humana, ciência, poder, linguagem, instituições sociais e transformação histórica.

Diante do cenário de estudos do empreendedorismo pode-se destacar uma perspectiva prática. Práticas de empreendedorismo têm sido estudadas por meio de encenações de improvisação e bricolagem (Baker \& Nelson, 2005; Johannisson, 2011; Imas, Wilson \& West, 2012; Watson, 2013), legitimação de risco (De Clercq \& Voronov, 2009), empreendedorismo de gênero (García \& Welter, 2015; Wheadon, \& Duval-Couetil, 2017) redes de empreendedorismo (Anderson, Dodd \& Jack, 2010; Johannisson, 2011; Mair, Battilana, \& Cardenas, 2012; Keating, Geiger \& McLoughlin, 2013), compreensão do contexto por empreendedores (Chalmers \& Shaw, 2016; Dey, \& Mason, 2018) e que promovem uma discussão sobre empreendedorismo com a perspectiva prática (Rindova, Barry \& Ketchen, 2009; Verduyn, 2015; Al-dajani, Carter, Shaw, \& Marlow, 2015; Jones \& Li, 2017). Para abordar os fenômenos foi desenvolvido 6 tabelas com subcategorias e contribuições dos autores para cada subcategoria.

Para a subcategoria Improvisação e Bricolagem como práticas (Tabela 1), se dedicam a uma forma de rigor que dialoga com inúmeros modos de produção de sentido e de conhecimento, que tem origem em diversos locais sociais com ações e interações entre todas as faculdades humanas (Baker \& Nelson, 2005; Johannisson, 2011).

Tabela 1

Subcategorias e contribuição da Improvisação e Bricolagem

\begin{tabular}{|c|c|c|c|}
\hline Ano & Autor (es) & Subcategorias & Contribuição \\
\hline 2005 & $\begin{array}{l}\text { Baker \& } \\
\text { Nelson }\end{array}$ & $\begin{array}{c}\text { Improvisação e } \\
\text { Bricolagem }\end{array}$ & $\begin{array}{l}\text { Cria valor econômico com recursos combinados geralmente } \\
\text { percebidos como sendo sem valor (ou pior, um passivo) e os } \\
\text { imbuem de novas oportunidades para entender a inovação e } \\
\text { melhorar um processo. }\end{array}$ \\
\hline 2011 & Johannisson & $\begin{array}{c}\text { Improvisação e } \\
\text { Bricolagem }\end{array}$ & $\begin{array}{l}\text { Processo emergente que enfoca ações e interações entre todas as } \\
\text { faculdades humanas, não apenas o cognitivo, mas também os } \\
\text { emocionais como instrumento na promulgação de novos } \\
\text { empreendimentos, seja no mercado ou em outros ambientes. } \\
\text { Uma visão construcionista convida diferentes modos de lidar } \\
\text { com um ambiente ambíguo, incluindo o uso de analogia e } \\
\text { bricolage ao promulgar empreender por meio de improvisação e } \\
\text { networking pessoal. }\end{array}$ \\
\hline 2012 & $\begin{array}{l}\text { Imas, } \\
\text { Wilson \& } \\
\text { West }\end{array}$ & $\begin{array}{c}\text { Improvisação e } \\
\text { Bricolagem }\end{array}$ & $\begin{array}{l}\text { Gera consciência relacional para desenvolver mercados e } \\
\text { apresenta uma extraordinária capacidade de crescimento e, } \\
\text { portanto, criar novas oportunidades para as pequenas empresas } \\
\text { terem sucesso e empoderarem-se. }\end{array}$ \\
\hline 2013 & Watson & $\begin{array}{c}\text { Improvisação e } \\
\text { Bricolagem }\end{array}$ & $\begin{array}{l}\text { A filosofia pragmatista nos encoraja a ver a atividade social } \\
\text { humana como um processo pelo qual os seres humanos se } \\
\text { esforçam criativamente para chegar a um acordo com as } \\
\text { circunstâncias em que encontram si mesmos. Atividades } \\
\text { empreendedoras podem prejudicar ou ajudar o bem público em } \\
\text { geral, dependendo da circunstância em que ocorrem, desta forma, } \\
\text { a ciência social pragmática tenta identificar a lógica subjacente a } \\
\text { qualquer tipo de atividade ou instituição, procura conhecimento }\end{array}$ \\
\hline
\end{tabular}


Partindo da Improvisação e Bricolagem (Tabela 1), encontra-se na prática dos processos o tempo de ação, habilidade e uma capacidade veloz e potente de produção para explorar e criar novos arranjos criando capacidades de crescimento e fortalecimento do empreendedor (Imas, Wilson \& West, 2012; Whatson, 2013). Já, na Legitimação de risco (Tabela 2) as capacidades de fortalecimento são evidenciadas como pontos fortes (De Clerq e Voronov, 2009).

Tabela 2

Subcategorias e contribuição da Legitimação de risco

\begin{tabular}{c|c|c|l}
\hline Ano & Autor (es) & Subcategorias & \multicolumn{1}{c}{ Contribuição } \\
\hline 2009 & $\begin{array}{c}\text { De Clercq } \\
\text { \& Voronov }\end{array}$ & $\begin{array}{c}\text { Legitimação de } \\
\text { risco }\end{array}$ & $\begin{array}{l}\text { A legitimidade como um potencial para o processo de } \\
\text { fortalecimento do empreendedor e de suas expectativas para que } \\
\text { os seus processos possam demonstrar funcionalidade eliminando } \\
\text { riscos. }\end{array}$ \\
\hline
\end{tabular}

De acordo com De Clerq e Voronov (2009) para que a prática do empreendimento seja executado com eficácia (Tabela2) é necessária a legitimidade como um potencial para o processo de fortalecimento do empreendedor e de suas expectativas para que os seus processos possam demonstrar funcionalidade, adaptando-se as mudanças e posto em prática com conhecimento e experiência, o que faz com que riscos possam ser eliminados. Para práticas de empreendedorismo de gênero (Garcia \& Welter, 2015; Wheadon, \& Duval-Couetil, 2017) ela permite uma construção da identidade de gênero na sociedade contemporânea (Tabela 3).

Tabela 3

Subcategorias e contribuição do Empreendedorismo de gênero

\begin{tabular}{c|c|c|l}
\hline Ano & Autor (es) & \multicolumn{1}{|c}{ Subcategorias } & \multicolumn{1}{c}{ Contribuição } \\
\hline \multirow{2}{*}{2015} & $\begin{array}{c}\text { García \& } \\
\text { Welter }\end{array}$ & $\begin{array}{c}\text { Empreendedorismo } \\
\text { de gênero }\end{array}$ & $\begin{array}{l}\text { Há formas específicas de construir a identidade de gênero que } \\
\text { resultam em práticas de como as mulheres agem fazendo e } \\
\text { refazendo permitindo que construam uma identidade do gênero } \\
\text { no estabelecimento da posição de status da mulher em relação ao } \\
\text { comportamento empreendedor. }\end{array}$ \\
\hline \multirow{2}{*}{2017} & $\begin{array}{l}\text { Wheadon, } \\
\text { \& Duval- } \\
\text { Couetil }\end{array}$ & $\begin{array}{l}\text { Empreendedoristencia sobre gênero no empreendedorismo seja sobre a } \\
\text { perspectiva da linguagem, associações e estereótipos } \\
\text { de gênero } \\
\text { incorporados em contextos empreendedores, tornam-se barreiras } \\
\text { culturais que sustentam a divisão tradicional do trabalho e criam } \\
\text { um sistema de dois níveis. A contínua falta de atenção às práticas } \\
\text { críticas e reflexivas na educação e pesquisa de } \\
\text { empreendedorismo, no entanto, ameaça a cumplicidade } \\
\text { disciplinar na opressiva "feminização (e racialização) da } \\
\text { pobreza" que existe na sociedade contemporânea. }\end{array}$ \\
\hline
\end{tabular}

Esse processo (Tabela 3) pode proporcionar vantagens como uma maior liberdade, realização, autonomia e independência financeira, assim como efeitos positivos quanto à satisfação originada pela atividade empreendedora possibilitando um desenvolvimento diferenciado e inovador na sociedade contemporânea (Garcia \& Welter, 2015; Wheadon, \& Duval-Couetil, 2017). A sociedade contemporânea possui a habilidade e capacidade empreendedora de operacionalizar acordos entre todas as partes interessadas (Tabela 4) e manter relações bem-sucedidas (Anderson, Dodd \& Jack, 2010; Mair, Battilana, \& Cardenas, 2012) fortalecendo as redes para um crescimento empresarial. 
Tabela 4

Subcategorias e contribuição de Redes de Empreendedorismo

\begin{tabular}{|c|c|c|c|}
\hline Ano & Autor (es) & Subcategorias & Contribuição \\
\hline 2010 & $\begin{array}{l}\text { Anderson, } \\
\text { Dodd \& } \\
\text { Jack }\end{array}$ & $\begin{array}{c}\text { Redes de } \\
\text { empreendedorismo }\end{array}$ & $\begin{array}{l}\text { As extensões específicas de práticas de rede que promulga o } \\
\text { processo de crescimento empresarial possibilita o crescimento } \\
\text { e interação social e promove oportunidades através das redes se } \\
\text { tornando um modo de ser Empreendedor, um mundo da vida } \\
\text { socialmente construída que não apenas espelha, mas (re) } \\
\text { apresenta o ambiente e ajuda a criar crescimento através de cinco } \\
\text { padrões de atividade que chamamos de intervalos de práticas: } \\
\text { libertadoras; inspiradoras; visionárias; articuladoras e } \\
\text { implementadoras dos processos. }\end{array}$ \\
\hline 2012 & $\begin{array}{c}\text { Mair, } \\
\text { Battilana, \& } \\
\text { Cardenas }\end{array}$ & $\begin{array}{c}\text { Redes de } \\
\text { empreendedorismo }\end{array}$ & $\begin{array}{l}\text { A análise baseia-se em quatro tipos de capital: político, humano, } \\
\text { econômico e social. O recente impulso na pesquisa de } \\
\text { empreendedorismo enfatiza as "formas de organização" e } \\
\text { "desdobramento cotidiano" do empreendedorismo como o foco } \\
\text { da análise empírica. O papel que a organização desempenha na } \\
\text { promulgação da mudança social é amplamente inexplorado. }\end{array}$ \\
\hline 2013 & $\begin{array}{c}\text { Keating, } \\
\text { Geiger \& } \\
\text { McLoughlin }\end{array}$ & $\begin{array}{c}\text { Redes de } \\
\text { empreendedorismo }\end{array}$ & $\begin{array}{l}\text { A compreensão dos recursos do empreendedorismo como uma } \\
\text { prática e de recursos sociais como algo que surge quando } \\
\text { empreendedores se envolvem nessas práticas. Isso significa que } \\
\text { o próprio ato de alcançar e engajar em recursos sociais muda essa } \\
\text { malha na qual a atividade empreendedora é incorporada e que o } \\
\text { empreendedor se adapte criativamente a uma rede de } \\
\text { interconexões em constante evolução. }\end{array}$ \\
\hline
\end{tabular}

As redes de empreendedorismo (Tabela 4) podem buscar a melhor combinação possível de diferentes recursos produtivos, situados dentro ou fora da empresa, criando uma unidade produtiva em melhores condições de negociar no mercado criando redes de interconexões (Keating, Geiger \& McLoughlin, 2013). A busca da compreensão do contexto por empreendedores (Tabela 5) permite criar e adotar práticas para construir uma organização (Chalmers \& Shaw, 2016).

Tabela 5

Subcategorias e contribuição da Compreensão do contexto por empreendedores

\begin{tabular}{|c|c|c|c|}
\hline Ano & Autor (es) & Subcategorias & Contribuição \\
\hline 2016 & $\begin{array}{c}\text { Chalmers \& } \\
\text { Shaw }\end{array}$ & $\begin{array}{l}\text { Compreensão do } \\
\text { contexto por } \\
\text { empreendedores }\end{array}$ & $\begin{array}{l}\text { Os contextos empresariais são, em primeiro lugar, uma } \\
\text { preocupação para os agentes empreendedores e com quem eles } \\
\text { interagem, pois, os papéis e identidades que os indivíduos } \\
\text { constroem através da interação cotidiana moldam e são moldada } \\
\text { pelas restrições contextuais que emergem e se dissipam durante } \\
\text { o curso de uma interação. }\end{array}$ \\
\hline 2018 & $\begin{array}{l}\text { Dey, \& } \\
\text { Mason }\end{array}$ & $\begin{array}{l}\text { Compreensão do } \\
\text { contexto por } \\
\text { empreendedores }\end{array}$ & $\begin{array}{l}\text { A capacidade do empreendedor ativista de abrir a imaginação a } \\
\text { realidades futuras alternativas pressupõe uma profunda } \\
\text { consciência do imaginário social. Ainda, que o empreendedor } \\
\text { ativista deve estar disposto e capaz de criticar imaginário social } \\
\text { ortodoxo e de imaginar mundos possíveis. A segunda condição } \\
\text { de fronteira lidava com a forma como os mundos possíveis se } \\
\text { tornam conhecido. }\end{array}$ \\
\hline
\end{tabular}

A compreensão do contexto por empreendedores (Tabela 5) requer uma capacidade de imaginação daqueles que constroem os negócios, pois os contextos são preocupações dos agentes empreendedores e estes precisam de capacidades na prática para lidar com o desconhecido (Dey, \& Mason, 2018). A prática do empreendedorismo (Tabela 6) pode ser um

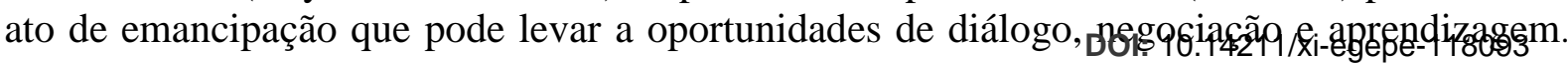


Tabela 6

Subcategorias e contribuição que Promovem uma discussão sobre empreendedorismo com a perspectiva prática

\begin{tabular}{|c|c|c|c|}
\hline Ano & Autor (es) & Subcategorias & Contribuição \\
\hline 2009 & $\begin{array}{l}\text { Rindova, } \\
\text { Barry \& } \\
\text { Ketchen }\end{array}$ & $\begin{array}{c}\text { Promovem uma } \\
\text { discussão sobre } \\
\text { empreendedorismo } \\
\text { com a perspectiva } \\
\text { prática }\end{array}$ & $\begin{array}{l}\text { A direção para a pesquisa de empreendedorismo é considerar que } \\
\text { o empreendedorismo ocorre em contextos tradicionalmente não } \\
\text { considerados no mainstream do empreendedorismo. É } \\
\text { importante que a pesquisa sobre empreendedorismo reconheça } \\
\text { que os empreendedores são muitas vezes um ato de emancipação } \\
\text { e atrai a atenção para os desafios que os empreendedores } \\
\text { enfrentam. Abordar essas oportunidades e desafios exigirá } \\
\text { abordagens que cruzem níveis de análise e se estendam além das } \\
\text { visões teóricas predominantes, integrando a teoria que permite } \\
\text { investigar os aspectos micro e macro do empreendedorismo. }\end{array}$ \\
\hline 2015 & Verduyn & $\begin{array}{c}\text { Promovem uma } \\
\text { discussão sobre } \\
\text { empreendedorismo } \\
\text { com a perspectiva } \\
\text { prática }\end{array}$ & $\begin{array}{l}\text { A perspectiva lefebvriana ressalta o empreendedorismo como um } \\
\text { processo complexo, não-linear, um fenômeno inerentemente } \\
\text { aberto. Esta perspectiva também está alinhada com as } \\
\text { conceituações existentes de empreender como um conglomerado } \\
\text { de práticas transindividuais propondo o rítmico como modo de } \\
\text { exploração. Com uma perspectiva lefebvriana, conceitua-se o } \\
\text { entrepreneuring como a inter-relação de vários ritmos, } \\
\text { dobrando-se e desdobrando-se, como ondas, produzindo uma } \\
\text { polirritmia híbrida, ocorrendo simultaneamente e propensa à } \\
\text { diferença. }\end{array}$ \\
\hline 2015 & $\begin{array}{l}\text { Al-dajani, } \\
\text { Carter, } \\
\text { Shaw, \& } \\
\text { Marlow }\end{array}$ & $\begin{array}{c}\text { Promovem uma } \\
\text { discussão sobre } \\
\text { empreendedorismo } \\
\text { com a perspectiva } \\
\text { prática }\end{array}$ & $\begin{array}{l}\text { O gênero e desenvolvimento do empreendedorismo } \\
\text { emancipatório e a eficácia das organizações atuam como uma } \\
\text { plataforma para revelar e explorar o potencial de empreender } \\
\text { como uma atividade emancipatória. }\end{array}$ \\
\hline 2017 & Jones \& Li & $\begin{array}{c}\text { Promovem uma } \\
\text { discussão sobre } \\
\text { empreendedorismo } \\
\text { com a perspectiva } \\
\text { prática }\end{array}$ & $\begin{array}{l}\text { Disposições, baseadas em hábitos, heurísticas e rotinas, } \\
\text { importantes em qualquer contexto empresarial, são } \\
\text { particularmente relevantes em start-ups familiares. Empresários } \\
\text { eficazes sabem que devem fazer o melhor possível com } \\
\text { informações ambíguas e recursos limitados. A conceituação da } \\
\text { mudança organizacional para ilustrar como os processos de } \\
\text { formação de sentido da encenação, seleção e retenção (ESR) } \\
\text { formaram com base em suas rotinas organizacionais nascentes. } \\
\text { Os processos associados ao ESR levaram a oportunidades de } \\
\text { diálogo, negociação e aprendizagem. }\end{array}$ \\
\hline
\end{tabular}

O empreendedorismo como prática (Tabela 6) promove discussão para que os processos de formação de sentido da encenação, seleção e retenção (ESR) formem uma base nas rotinas organizacionais. Os processos associados ao ESR levam a oportunidades de diálogo, negociação e aprendizagem colaborando para que os empresários possam emancipar-se (Aldajani, Carter, Shaw, \& Marlow, 2015; Jones \& Li, 2017).

O empreendedorismo, como um comportamento criativo e proativo (Figura 2), se apresenta como um fenômeno em movimento, complexo, não-linear e inerentemente aberto, promovendo esforços para criar novos ambientes econômicos, sociais, institucionais e culturais por meio das ações de um indivíduo ou grupo de indivíduos. O empreendedorismo como prática, ou entrepreneuring, é um processo social criativo e situado organizacionalmente, que materializa uma nova organização ou novas práticas organizacionais, a partir de decisões e ações executadas por praticantes empreendedores que organizam pessoas e recursos, que criam, descobrem, identificam e exploram oportunidades com comportamentos criativos e proativos. 


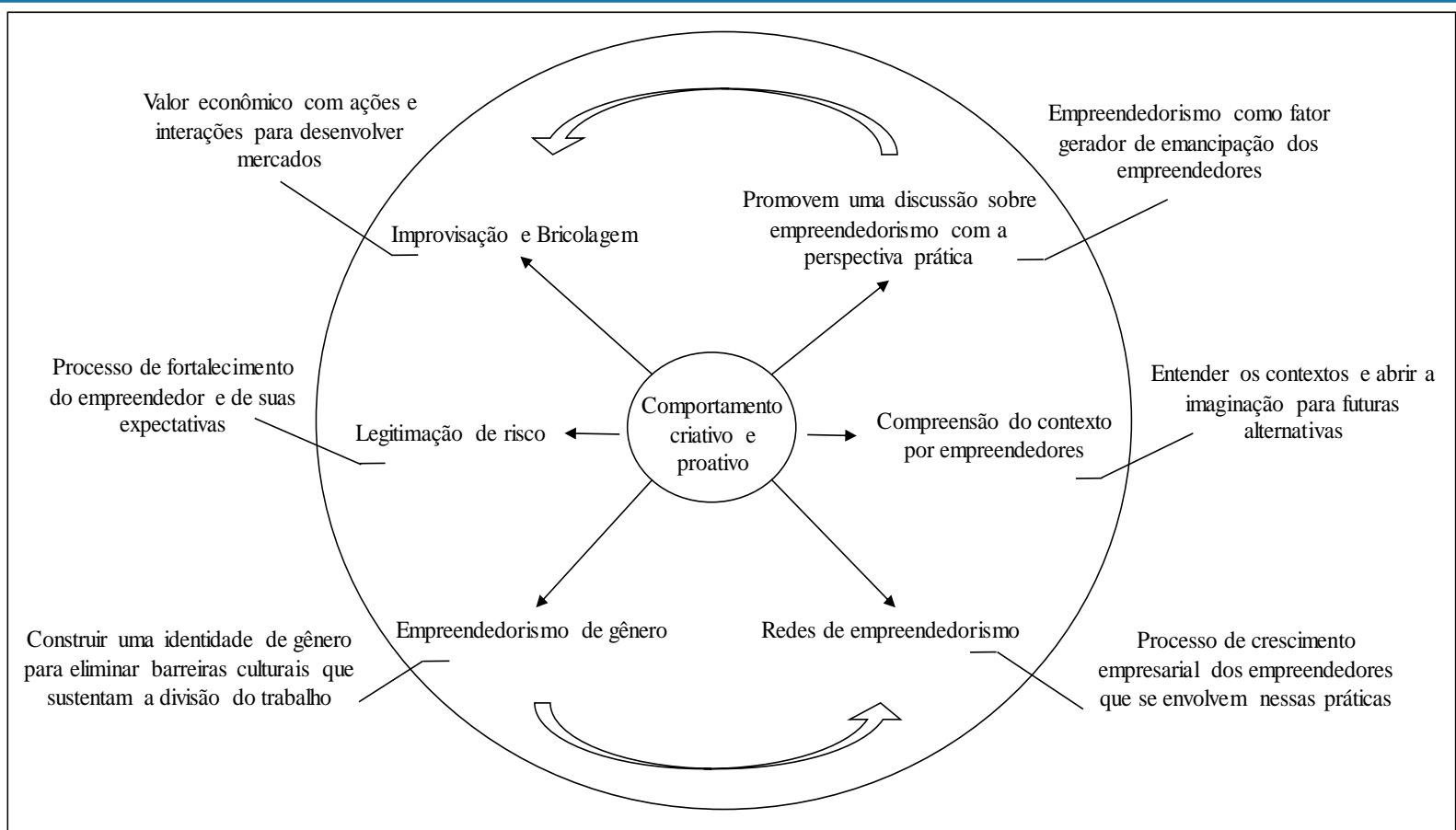

Figura 2 - Dimensões do empreendedorismo como prática

As subcategorias apresentam contribuições explicadas por autores ao longo do tempo (Figura 2). Ao abordarem o tema, constatou-se que os processos de transformação requerem dos indivíduos empreendedores um comportamento proativo e criativo, aptos a definir os parâmetros daquilo que se pretende realizar e quais os meios a serem utilizados. Desta forma, as práticas de empreendedorismo são formas rotineiras em que os profissionais de empreendedorismo movem corpos, manipulam objetos, tratam assuntos, descrevem coisas e compreendem o mundo. $\mathrm{O}$ empreendedorismo como uma perspectiva prática, incorpora os meios disponíveis e é preciso assumir riscos e agir de forma criativa e proativa.

\section{Considerações Finais}

Este trabalho buscou compreender a evolução das discussões sobre a abordagem entrepreneuring no campo de estudo do empreendedorismo e retratou subcategorias com as constituições. O estudo evidencia por meio de uma revisão da literatura sua evolução e seus reflexos no campo de estudo. Como procedimento metodológico utilizou-se uma revisão de literatura. Este trabalho contribui para a reflexão sobre a abordagem entrepreneuring e suas contribuições para o campo de estudo do empreendedorismo. O entrepreneuring, assim, se apresenta como um fenômeno complexo, não-linear e inerentemente aberto, promovendo esforços para criar novos ambientes econômicos, sociais, institucionais e culturais por meio das ações de um indivíduo ou grupo de indivíduos.

A atuação do praticante, surge como a ação empreendedora na prática e envolvendo rotinas de compreender, conhecer, agir e fazer repercutindo nas atividades das organizações. A prática, pode contribuir de maneira efetiva para a pesquisa em empreendedorismo, e abordamos como implicações a contribuição para a teoria e gerencialmente para o vigor do fenômeno e da importância do comportamento criativo e proativo, constituindo assim, alternativas interessantes de desenvolvimento do campo de pesquisas. Embora nossos resultados sugiram que ocorram contribuições para a teoria e o campo gerencial, esperamos que nossos esforços forneçam uma base para futuros estudos empíricos como uma maneira de expandir o

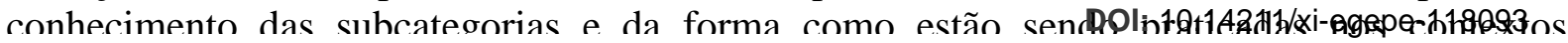




\section{Referências}

Akobeng, A. K. (2005). Understanding systematic reviews and meta-analysis. Archives of disease in childhood, 90(8), 845-848.

Al-Dajani, H., Carter, S., Shaw, E., \& Marlow, S. (2015). Entrepreneurship among the displaced and dispossessed: Exploring the limits of emancipatory entrepreneuring. British Journal of Management, 26(4), 713-730.

Aldrich, H. E., \& Yang, T. (2014). How do entrepreneurs know what to do? Learning and organizing in new ventures. Journal of Evolutionary Economics, 24(1), 59-82.

Anderson, A. R., Dodd, S. D., \& Jack, S. (2010). "Network Practices and Entrepreneurial Growth." Scandinavian Journal of Management 26: 121-33. doi:10.1016/j.scaman.2010.01.005.

Baker, T., \& Nelson, R. E. (2005). "Creating Something from Nothing: Resource Construction through Entrepreneurial Bricolage." Administrative Science Quarterly 50 (3): 329-66. doi: 10.2189/asqu.2005.50.3.329.

Bardin, L. (2011). Análise de conteúdo. Tradução de Luís Antero Retos, Augusto Pinheiro. São Paulo: Edições, 70.

Baron, R., \& Shane, S. A. (2007). Empreendedorismo: uma visão do processo. São Paulo: Thompson.

Bourdieu, P. (1990). The Logic of Practice. Cambridge, England: Polity Press.

Born, G. (2010). For a relational musicology: music and interdisciplinarity, beyond the practice turn: the 2007 Dent Medal Address. Journal of the Royal Musical Association, 135(2), 205-243.

Brown, C. (2012). The 'practice turn', phronesis and classical realism: Towards a phronetic international political theory? Millennium, 40(3), 439-456.

Bruyat, C., \& Julien, P. A. (2001). Defining the field of research in entrepreneurship. Journal of Business Venturing, v. 16, n. 2, p. 165-180, mar.

Chalmers, D., \& Shaw, E. (2015). "The Endogenous Construction of Entrepreneurial Contexts: A Practice-Based Perspective." International Small Business Journal 1-21. doi:10.117 7/0266242615589768.

Davidsson, P. (2004). Researching entrepreneurship. New York: Springer.

De Clercq, D., \& Voronov, M. (2009). "Toward a Practice Perspective of Entrepreneurship: Entrepreneurial Legitimacy as Habitus." International Small Business Journal 27 (4): 395419. doi: 0.1177/0266242609334971.

Dey, P., \& Mason, C. (2018). Overcoming constraints of collective imagination: An inquiry into activist entrepreneuring, disruptive truth-telling and the creation of 'possible worlds'. Journal of business venturing, 33(1), 84-99.

Drucker, P. F. (1985). The changed world economy. Foreign Aff., 64, 768.

Engstrom, C. (2012). An autoethnographic account of prosaic entrepreneurship. Tamara: Journal for Critical Organization Inquiry, 10(1-2).

Farah, O. E., Cavalcanti, M., \& Marcondes, L. P. (2008). Empreendedorismo Estratégico: Criação e gestão de pequenas empresas. $2^{a}$ ed. São Paulo: Cengage Learning.

Fisher, G. (2012). Effectuation, causation, and bricolage: a behavioral comparison of emerging theories in entrepreneurship research. Entrepreneurship Theory and Practice, 36(5), 10191051. doi: 10.1111/j.1540-6520.2012.00537.x

Felix, F. V., Oliveira, S. A. (2019). Empreendedorismo como uma Prática Socialmente Imersa: Contribuições Institucionalistas. Anais do XLIII Encontro da ANPAD - EnANPAD 2019.

Garcia, M. C. D., \& Welter, F. (2015). "Gender Identities and Practices: Interpreting Women Entrepreneurs' Narratives.” International Small Business Journal doi:10.1177/02662 
Gartner, W. B. (1985). A Conceptual Framework for Describing the Phenomenon of New Venture Creation. Academy of Management Review, v. 10, n. 4, p. 696-706.

Giddens, A. (1982). A reply to my critics. Theory, Culture \& Society, 1(2), 107-113.

Gross, N., Carson, D., \& Jones, R. (2014). "Beyond Rhetoric: Re-Thinking Entrepreneurial Marketing from a Practice Perspective." Journal of Research in Marketing and Entrepreneurship 16 (2): 105-27. doi.org/10.1108/JRME-01-2014-0003.

Hisrich, R. D., Peters, M. P., \& Shepherd, D. A. (2009). Empreendedorismo. Tradução de Teresa Cristina Felix de Souza. 7. ed. Porto Alegre: Bookman.

Hjorth, J., Sollerman, J., Møller, P., Fynbo, J. P., Woosley, S. E., Kouveliotou, C., \& Cerón, J. M. C. (2003). A very energetic supernova associated with the $\gamma$-ray burst of 29 March 2003. Nature, 423(6942), 847.

Imas, J. M., Wilson, N., \& Weston, A. (2012). "Barefoot Entrepreneurs.” Organization 19 (5): 563- 85. doi:10.1177/1350508412459996.

Jarzabkowski, P., Balogun, J., \& Seidl, D. (2007). Strategizing: The challenges of a practice perspective. Human relations, 60(1), 5-27.

Johannisson, B. (2011). "Towards a Practice Theory of Entrepreneuring." Small Business Economics 36 (2): 135-50. doi:10.1007/s11187-009-9212-8.

Jones, O., \& Li, H. (2017): Effectual entrepreneuring: sensemaking in a family-based start-up, Entrepreneurship \& Regional Development, DOI: 10.1080/08985626.2017.1297854

Keating, A., Geiger, S., \& Mcloughlin, D. (2013). "Riding the Practice Waves: Social Resourcing Practices During New Venture Development." Entrepreneurship Theory and Practice 1-29. doi:10.1111/etap.12038.

Kincheloe, J. L. (2001). Describing the Bricolage: conceptualizing a new rigor in Qualitative Research. Qualitative Inquiry, v.7, n.6, p.679-692.

Kustermans, J. (2016). Parsing the practice turn: Practice, practical knowledge, practices. Millennium, 44(2), 175-196.

Landström, H., Harirchi, G., \& Aström, F. (2012). Entrepreneurship: Exploring the Knowledge base. Research Policy, v. 41, n. 7. p. 1154-1181, set.

Lévi-Strauss, C. (1970). O pensamento selvagem. São Paulo: Editora Nacional e Editora da USP.

Lincoln, Y. S. (2001). An emerging new bricoleur: promises and possibilities - a reaction to Mair, J., Battilana, J., \& Cardenas, J. (2012). Organizing for society: A typology of social entrepreneuring models. Journal of business ethics, 111(3), 353-373.

Lodhia, S., \& Jacobs, K. (2013). The practice turn in environmental reporting: A study into current practices in two Australian commonwealth departments. Accounting, Auditing \& Accountability Journal, 26(4), 595-615.

Maciel, C. D. O., \& Mussi, A. P. O. M. (2013). A practice turn e o movimento social da estratégia como prática: está completa essa virada? RAM. Revista de Administração Mackenzie, 14(2), 155-178.

Orr, J. E. (1996). Talking About Machines: An Ethnography of a Modern Job. Ithaca, NY: ILP Press. Schatzki,

Pinchot III, G. (1985). Intrapreneuring: Why you don't have to leave the corporation to become an entrepreneur. University of Illinois at Urbana-Champaign's. Academy for Entrepreneurial Leadership Historical Research Reference in Entrepreneurship.

Raelin, J. A. (2009). The practice turn-away: Forty years of spoon-feeding in management education. Management Learning, 40(4), 401-410.

Reed, P. G. (2006). The practice turn in nursing epistemology. Nursing Science Quarterly, 19(1), 36-38.

Reid, J. A. (2011). A practice turn for teacher education? Asia-Pacific Journal of Teacher 
Rindova, V., Barry, D., \& Ketchen, D. J. (2009). Entrepreneuring as Emancipation. Academy of Management Review, 34(3), 477-491.doi:10.5465/amr.2009.40632647

Ross, D. G., \& Shin, D. H. (2019). Women and Entrepreneurship: A Comprehensive MetaAnalysis. Available at SSRN 3259596.

Sarasvathy, S. D. (2001a). Causation and effectuation: toward a theorial shift from economic inevitability to entrepreneurial contigency. Academy of Management Review, 26(2), 243263. Retrieved from http://www.jstor.org/stable/259121

Sarasvathy, S. D. (2008). Effectuation: elements of entrepreneurial expertise. Massachussets, USA: Edward Elgar Publishing, Inc.

Sarasvathy, S. D., \& Venkataraman, S. (2011). Entrepreneurship as method: open questions for an entrepreneurial future. Entrepreneurship Theory and Practice, 35(1), 113-135. doi: $10.1111 / \mathrm{j} .1540-6520.2010 .00425 . \mathrm{x}$

Schatzki, T. (2001). Introduction: practice theory. The practice turn in contemporary theory.

Schumpeter, J. (1982). A teoria do desenvolvimento econômico (1912). São Paulo: Ed.

Shane, S. A. (2003). General theory of entrepreneurship: the individual-opportunity nexus. North Hanpton: Edward Elgar.

Shane, S., \& Venkataraman, S. (2000). The promise of entrepreneurship as a field of research. Academy of Management Review, v. 25. n. 1. p. 217-226, jan.

Sorenson, O., Rivkin, J. W., \& Fleming, L. (2006). Complexity, networks and knowledge flow. Research policy, 35(7), 994-1017.

Spigel, B., \& Harrison, R. (2018). Toward a process theory of entrepreneurial ecosystems. Strategic Entrepreneurship Journal, 12, p. 151-168.

Steyaert, C. (2007). “"Entrepreneuring' as a Conceptual Attractor? A Review of Process Theories in 20 Years of Entrepreneurship Studies." Entrepreneurship and Regional Development 19 (6): 453-|77. doi:10.1080/08985620701671759.

Steyaert, C., \& Katz, J. (2004). Reclaiming the space of entrepreneurship in society: geographical, discursive and social dimensions. Entrepreneurship \& regional development, 16(3), 179-196.

Stockhammer, P. W. (2012). Performing the practice turn in archaeology. The Journal of Transcultural Studies, (1), 7-42.

Theodore, R. (2001). "Practice Theory: An Introduction." In: The Practice Turn in Contemporary Theory, edited by Theodore R. Schatzki, Karin Knorr-Cetina, and Eike von Savigny, 1-14. London: Routledge. Schatzki,

Verduyn, K. (2015). Entrepreneuring and process: A Lefebvrian perspective. International Small Business Journal, 33(6), 638-648.

Watson, T. J. (2013). "Entrepreneurship in Action: Bringing Together the Individual, Organizational and Institutional Dimensions of Entrepreneurial Action." Entrepreneurship and Regional Development 25 (5-6): 1-19. doi:10.1080/08985626.2012.754645.

Wheadon, M., \& Duval-Couetil, N. (2017). Entrepreneuring gender diversity in entrepreneurship through critical theory and reflexivity. International Journal of Gender and Entrepreneurship, 9(2), 188-202. doi:10.1108/ijge-02-2017-0010

Whittington, R. (2006). "Completing the Practice Turn in Strategy Research." Organization Studies 27 (5): 613-34. doi:10.1177/0170840606064101.

Whittington, R. (2011). The practice turn in organization research: Towards a disciplined transdisciplinarity. Accounting, organizations and society, 36(3), 183-186.

Wright, M., \& Marlow, S. (2012). Entrepreneurial activity in the venture creation and development process. International Small Business Journal, 30(2), 107-114.

Yearworth, M., Ormerod, R., \& White, L. (2019). Problem structuring interventions in practice? Management Studies Business School. 
York, J. G., \& Venkataraman, S. (2010). The entrepreneur-environment nexus: Uncertainty, innovation, and allocation. Journal of Business Venturing doi:10.1016/j.jbusvent.2009.07.007

O presente trabalho foi realizado com apoio da Coordenação de Aperfeiçoamento de Pessoal de Nível Superior - Brasil (CAPES) - Código de Financiamento 001.

This study was financed with support the Coordination of Improvement of Higher Education Personnel - Brazil (CAPES) - Finance Code 001. 